\title{
The dynamic development of bacterial community following long- term weathering of bauxite residue
}

by Wu, H., Chen, L., Zhu, F., Hartley, W., Zhang, Y. and Xue, $S$.

Copyright, publisher and additional Information: This is the author accepted manuscript. The final published version (version of record) is available online via Elsevier.

This version is made available under the CC-BY-ND-NC licence:

https://creativecommons.org/licenses/by-nc-nd/4.0/legalcode

Please refer to any applicable terms of use of the publisher

DOI: https://doi.org/10.1016/i.jes.2019.12.001

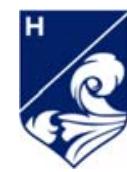




\title{
The dynamic development of bacterial community following long-term weathering of bauxite residue
}

\author{
Hao $\mathrm{Wu}^{1}$, Li Chen ${ }^{1}$, Feng Zhu' ${ }^{1}$, William Hartley ${ }^{2}$, Yifan Zhang ${ }^{1}$, Shengguo Xue ${ }^{1}$ \\ ${ }^{1}$ School of Metallurgy and Environment, Central South University, Changsha 410083, China \\ ${ }^{2}$ Crop and Environment Sciences Department, Harper Adams University, Newport, Shropshire TF10 8NB, UK
}

\begin{abstract}
Bauxite residue disposal areas (BRDAs) are typically bare of vegetation with high salinity and alkalinity. However, spontaneous encroachment of vegetation indicated that natural weathering processes had transformed the residue tailings into a soil-like material. Here we investigate the development of bacterial communities and their geochemical drivers in bauxite residue, using Illumina high-throughput sequencing technology. Bauxite residue from weathered sites had lower $\mathrm{pH}$ and exchangeable sodium percentages (ESP), but greater organic carbon and nitrogen concentrations. Following natural processes, the diversity of the bacterial community significantly increased and hierarchical clustering separated un-weathered from older weathered sites. Taxonomic analysis revealed that long-term weathering processes encouraged populations of Proteobacteria, Chloroflexi, Acidobacteria and Planctomycetes, whilst reducing populations of Firmicutes and Actinobacteria. LEfSe analysis revealed that the biomarker changed considerably in older weathered residues compared with that of un-weathered residue. Amongst all the residue properties, variation in total organic carbon (TOC), total nitrogen (TN), available phosphorus (AP) and $\mathrm{pH}$, showed significant effects on the diversity and structures of the bacterial community. The results have demonstrated that natural weathering processes stimulate the dynamic development of bacterial communities in bauxite residue, and may provide a hypothetical basis for the application of microbes at disposal areas to improve soil conditions.
\end{abstract}

\section{HIGHLIGHT:}

- Development of microbial communities in bauxite residue disposal areas following long-term natural processes was investigated.

Natural processes promoted the diversity of bacterial communities in bauxite residue.

- Bacterial community structure significantly differed in weathered disposal areas

pH, TOC, TN and AP may be the most important factors influencing bacterial community structure in bauxite residue.

KEY WORD: Bauxite residue; Weathering; Bacterial diversity; Bacterial community; Illumina high-throughput sequencing 


\section{Introduction}

Bauxite residue, an industrial waste produced during the production of alumina, represents a large and increasing global problem (Gomes et al., 2016). Currently, the worldwide inventory reached an estimated 4.2 billion tons, increasing by approximately 200 million tons per annum (Xue et al., 2019). Bauxite residue is rarely recycled and is frequently stored in bauxite residue disposal areas (BRDAs) (Power et al., 2011). Therefore, the growing mass of stored bauxite residue highlights the need for strategies to manage this growing problem, and in situ revegetation may be a promising way towards this (Xue et al., 2016).

Bauxite residue often presents high alkalinity and salinity, as well as a lack of nutrients, which largely hinder plant growth (Jones and Haynes, 2011). Currently, various amendments are applied prior to vegetation establishment to render the residue more hospitable to plants (Courtney and Harrington, 2012; Courtney and Kirwan, 2012; Fuller et al., 1982; Wong, 1993). However, no study has documented long-term successful revegetation on BRDAs.

Successful revegetation must involve the development of microbially-driven nutrient cycling for the long-term provision of plant nutrients (Grandlic et al., 2008; Rashid et al., 2016). Different microbes perform diverse functions during soil nutrient cycling such as, decomposition of organic matter and leaf litter (Schweinsberg-Mickan and Muller, 2009), mobilization and translocation of inorganic mineral nutrients (Nassal et al., 2018) and fixation of atmospheric carbon and nitrogen (Lynn et al., 2017). In addition, many plant species benefit from symbiotic associations with soil microorganisms such as mycorrhizal fungi and rhizobia (Kuiper et al., 2004). Studies on mine tailings have emphasized a strong association between the establishment of a stable plant community and the abundance and composition of soil microbiota (Chen et al., 2008; Dhawi et al., 2016; Mendez and Maier, 2008). For instance, arbuscular mycorrhizal fungi (AMF) commonly assist in the recovery of soil organic carbon and nitrogen in coal mine districts. Plant growth-promoting bacteria (PGPB) are also successful in promoting the establishment of vegetation on metallic mine tailings.

For rehabilitation on bauxite residues, microbial communities also appear to be essential. Fe example, the addition of organic amendments increased soluble organic $\mathrm{C}$, microbial biomass $\mathrm{C}$, basal respiration and promoted enzyme activities (Jones et al., 2010; Jones et al., 2011). The diversity of bacterial and fungal communities developed rapidly and was similar to that in a coastal sand analog (Banning et al., 2011). In addition, long-term restoration also created diverse soil-like microbial communities as environmental conditions became less extreme indicating the potential for feedback to exist between microbial communities and their environment which may be exploited in the development of microbially-driven remediation strategies (Schmalenberger et al., 2013). However, we know of no published studies investigating the successional development of microbial community structure and function in bauxite residue following weathering over time. Recently, spontaneous vegetation growth on abandoned BDRAs suggested that natural weathering processes could improve bauxite residue and support vegetation establishment. Although natural weathering processes improved the properties of bauxite residue and promoted plant establishment (Kong et al., 2017b; Zhu et al., 2016), microbial diversity and functional community structure remained elusive. In this study we use high-throughput sequencing and real-time quantitative PCR technology in an attempt to identify the microbial community structure and functional genes involved in $\mathrm{C}$ and $\mathrm{N}$ cycling within bauxite residue at their different stages of weathering. 
We hypothesize that natural weathering processes have changed the diversity and structural composition of the microbial communities and in doing so have improved the properties of bauxite residue over time in order to support plant establishment. Thus, the objectives of this investigation were to, (a) investigate the effect of weathering processes on bacterial community diversity, 2) identify the changes in bacterial community structure at the weathered disposal area and, 3) reveal potential influencing factors which affect bacterial community structure in bauxite residue.

\section{Materials and methods}

\subsection{Site description and sampling}

The selected bauxite residue disposal area (BRDA) is located in Central China $\left(35^{\circ} 24^{\prime} \mathrm{N}, 113^{\circ}\right.$ $25^{\prime} \mathrm{E}$ ) and was in operation for 20 years from 1993 to 2013. The climate is temperate continental monsoon, with an average temperature of $12.8-14.8{ }^{\circ} \mathrm{C}$ and average precipitation of $874 \mathrm{~mm}$. Residue samples were collected during October, 2018. Based on the time of deposition and vegetation cover, four sampling sites were selected; unweathered site (UW), young weathered site (YW), old weathered site (OW) and old weathered site with grass (OWV). These locations were used to evaluate the influence of natural regeneration on the bacterial community (Table 1). The OWV sites were mainly dominated by Cynodon dactylon. For each site, residue samples were collected to a depth of 0-20 cm in triplicate using an auger with a $10 \mathrm{~cm}$ diameter (Fig. 1).

All samples were brought back to the laboratory and divided into two parts. One part was dried at room temperature and then sieved $(<2 \mathrm{~mm})$ for physicochemical analyses. The second part was prepared under $-80^{\circ} \mathrm{C}$ in the laboratory for microbial analyses.
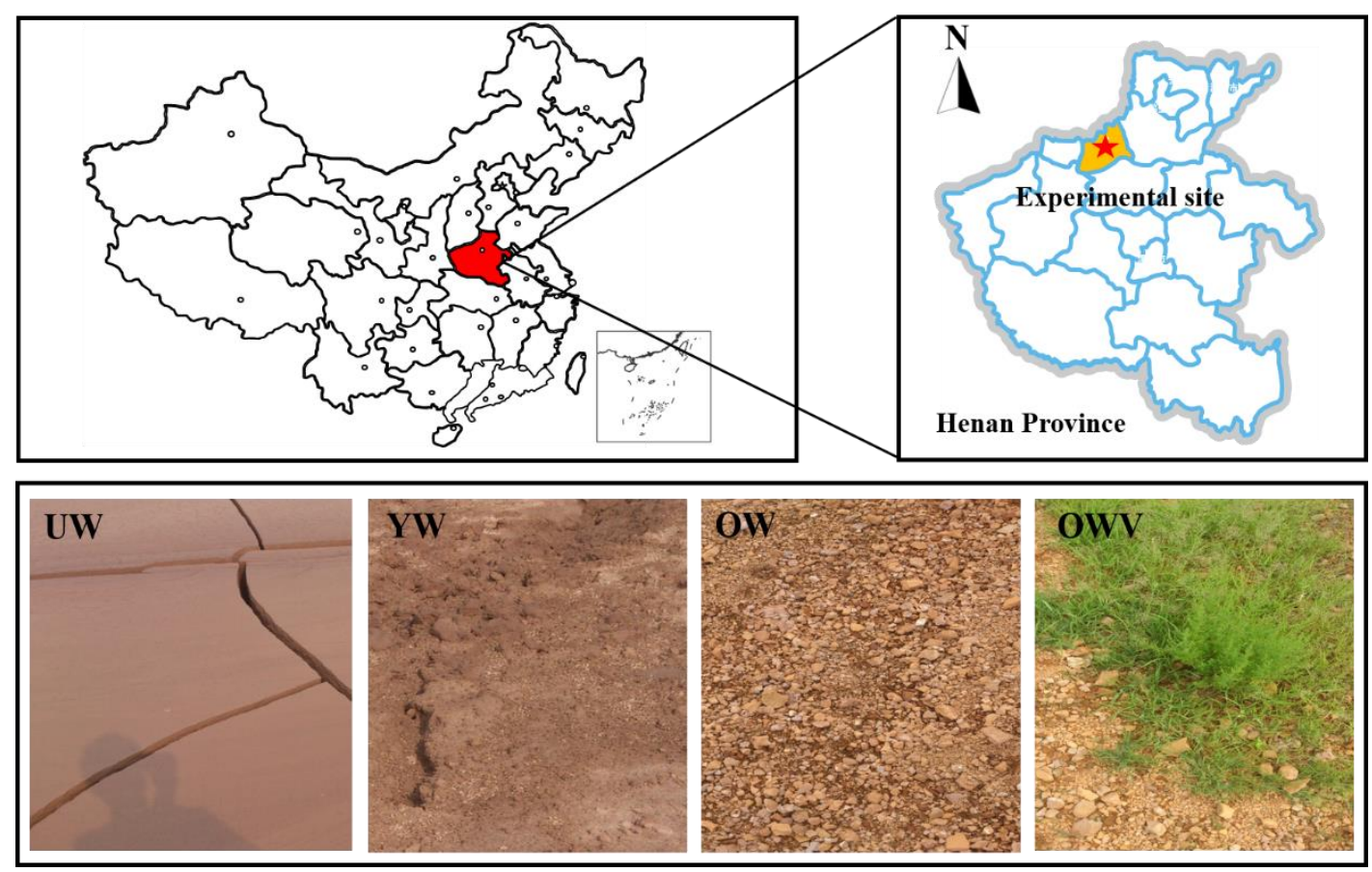

Fig. 1. The effect of weathering on bauxite residue at different temporal stages following disposal. UW: unweathered residue; YW: young weathered residue; OW: old weathered residue; OWV: old weathered residue covered with vegetation. 


\subsection{Determination of residue properties}

$\mathrm{pH}$ and $\mathrm{EC}$ were analyzed by water extraction with a ratio of $1: 5(\mathrm{w} / \mathrm{w}$, solid/liquid) using a $\mathrm{pH}$ detector and a conductivity meter, respectively (Rayment and Higginson, 1992). Exchangeable Ca, Mg, $\mathrm{K}$, and $\mathrm{Na}$ were extracted with $1 \mathrm{M}$ ammonium acetate and analyzed by ICP-AES (Rayment and Higginson, 1992). Exchangeable sodium percentage (ESP) was calculated by the proportion of exchangeable sodium in the total exchangeable bases. Total organic carbon (TOC) was determined by low-temperature external-heat potassium dichromate oxidation colorimetric method. Total nitrogen (TN), ammonium and nitrate concentrations were determined by an automated flow injection analyzer after extraction of the soil samples with $2 \mathrm{M} \mathrm{KCl}$. Available phosphorus was extracted with $0.5 \mathrm{M}$ $\mathrm{NaHCO}_{3}(\mathrm{pH} 8.5)(1: 100 \mathrm{w} / \mathrm{v}$ ratio for $16 \mathrm{~h})$ and measured using UV spectrophotometry by the molybdenum blue method.

\subsection{DNA extraction and PCR amplification}

DNA extraction was carried out using the Ultra Clean Soil DNA extraction kit from MoBio (Carlsbad, CA) according to the manufacturer's instructions. Extracted DNA was quantified using a Nano Drop ND-1000 (Thermo Scientific, Waltham, MA). The V4 region of the bacterial 16S rRNA gene was amplified with the primers $338 \mathrm{~F}$ and 806R.

All PCRs were conducted in a G-Storm GS2 thermo-cycler (Somerset, UK) with primers obtained from Metabion (Munich, Germany). DNA was amplified via PCR using established protocols with 0.5 U of Dreamtaq polymerase, $1 \times$ buffer with $2 \mathrm{mM} \mathrm{Mg}, 0.2 \mathrm{mM}$ dNTP each (all Fermentas, Germany) and $0.4 \mu \mathrm{M}$ primer each in a total volume of $25 \mu \mathrm{L}$. The PCR was performed under the following conditions: $94{ }^{\circ} \mathrm{C}(180 \mathrm{~s}) ; 28$ cycles of $94{ }^{\circ} \mathrm{C}(30 \mathrm{~s}), 53{ }^{\circ} \mathrm{C}(40 \mathrm{~s})$, and $72{ }^{\circ} \mathrm{C}(60 \mathrm{~s})$; and $72{ }^{\circ} \mathrm{C}(300 \mathrm{~s})$. Amplicon products were purified using the Agencourt AMPure PCR Purification system (Beckman Coulter, Indianapolis, IN). Briefly, $180 \mathrm{mg}$ of residue was incubated with $1 \mathrm{M} \mathrm{CaCO}_{3}$ solution for $1 \mathrm{hr}$ and subsequently extracted by the phenol-chloroform method. DNA extracts were purified using a GenecleanTurbo Kit (Biogenic), following the manufacturer's instructions, and the replicates of each sample were pooled together and stored in $-20^{\circ} \mathrm{C}$ before further use.

\subsection{Data analysis and statistical procedures}

Sequence reads were first analyzed using the Qiime pipeline. Briefly, operational taxonomical units were clustered with a similarity cut off at $97 \%$ and diversity analysis was calculated, resulting in alpha and beta diversity analysis based on sequences that exceeded 54,000 reads in total.

The estimation of microbial diversities of the bauxite residue sites were conducted via QIIME platform. Taxonomic analysis of sequences was implemented with a combination of BLAST 30 against the 16S-specific SILVA database (version 100) and MEGAN 431 with a bit-score cutoff of 86. Sequences of selected families were exported into Mega 532 for alignment and import of related sequences using the BLAST tool. Realigned sequences were used for maximum likelihood tree generation (Jukes-Cantor).

Statistical analysis of fungal community profiles was performed using the STAMP software (Parks et al., 2014) following the Two-sided Welch's t-test. Alpha-diversity and beta-diversity of fungal communities were calculated on the $\mathrm{R}$ statistical platform, using the 'vegan' package. Alpha-diversity included observed OTU number, Chao1, Shannon diversity index (H), Simpson index of diversity (1/D) and Pielou evenness index (J). Beta diversity of comparing fungal community structure in different treatments including correspondence analysis (CA), Nonmetric Multidimensional 
Scaling (NMDs) and analysis of similarity (ANOSIM) were carried out based on the Bray-Curtis distance matrix. Canonical correspondence analysis (McCarthy and Williams) was employed to reveal the relationship between soil properties and the fungal community. LEfSe (Linear discriminant analysis Effect Size) for detecting biomarkers was performed on the online Galaxy platform. Student t-test was performed to compare the significant difference between two groups using Minitab software. A $p$ value of less than 0.05 was considered as significant.

\section{Results}

\subsection{Residue properties}

Residue sample properties significantly differed during the natural weathering processes (Table 1). The unweathered residue (UW) presented high alkalinity and salinity, as well as a lack of nutrients. Values of $\mathrm{pH}, \mathrm{EC}$, and ESP significantly decreased as weathering time increased $(\mathrm{P}<0.05)$, whereas the contents of TOC, TN, and AP significantly increased as weathering time increased $(\mathrm{P}<0.05$, Table 1).

Table 1 Characteristics of residue samples from the different stages of weathering

\begin{tabular}{cccccc}
\hline Samples & & UW & YW & OW & OWV \\
\hline $\mathrm{pH}$ & & $11.03 \pm 0.11 \mathrm{D}$ & $10.6 \pm 0.07 \mathrm{C}$ & $10.1 \pm 0.09 \mathrm{~B}$ & $9.4 \pm 0.10 \mathrm{~A}$ \\
$\mathrm{EC}^{\mathrm{b}}$ & $\mathrm{mS} \cdot \mathrm{cm}^{-1}$ & $3.65 \pm 0.57 \mathrm{D}$ & $2.28 \pm 0.49 \mathrm{C}$ & $0.92 \pm 0.16 \mathrm{~B}$ & $0.34 \pm 0.02 \mathrm{~A}$ \\
$\mathrm{ESP}^{\mathrm{c}}$ & $\%$ & $72.51 \pm 0.32 \mathrm{D}$ & $49.65 \pm 1.98 \mathrm{C}$ & $34.72 \pm 1.36 \mathrm{~B}$ & $28.99 \pm 1.19 \mathrm{~A}$ \\
$\mathrm{TOC}^{\mathrm{d}}$ & $\mathrm{g} \cdot \mathrm{kg}^{-1}$ & $5.71 \pm 0.26 \mathrm{~A}$ & $8.00 \pm 0.30 \mathrm{~B}$ & $9.24 \pm 0.25 \mathrm{C}$ & $10.81 \pm 1.15 \mathrm{D}$ \\
$\mathrm{TN}^{\mathrm{e}}$ & $\mathrm{g} \cdot \mathrm{kg}^{-1}$ & $0.039 \pm 0.008 \mathrm{~A}$ & $0.150 \pm 0.06 \mathrm{~B}$ & $0.729 \pm 0.07 \mathrm{C}$ & $1.532 \pm 0.28 \mathrm{D}$ \\
$\mathrm{AP}$ & $\mathrm{mg} \mathrm{kg}$ & $5.32 \pm 0.25 \mathrm{~A}$ & $10.48 \pm 0.25 \mathrm{~B}$ & $22.74 \pm 5.44 \mathrm{C}$ & $34.94 \pm 5.44 \mathrm{D}$ \\
\hline
\end{tabular}

UW: unweathered site; YW: young weathered site; OW: old weathered site; OWV: old weathered with vegetation covert;

$\mathrm{EC}=$ electrical conductivity $; \mathrm{ESP}=$ exchangeable sodium percentage $; \mathrm{TOC}=$ total organic carbon; $\mathrm{TN}=$ total nitrogen;

$\mathrm{AP}=$ available phosphorus; $\mathrm{mS}=$ milli Siemens; $\mathrm{abc}=$ significantly different $(\mathrm{P}<0.05) ; \pm=$ standard deviation.

With the same weathering time, the values of $\mathrm{pH}, \mathrm{EC}$, and ESP were significantly higher at unvegetated sites (OW) compared to vegetated areas $(\mathrm{OWV})(\mathrm{P}<0.05)$. At the same time, the concentrations of TOC, TN, and AP were significantly lower in unvegetated sites (OW) than those in vegetated areas $(\mathrm{OWV})(\mathrm{P}<0.05)$.

\subsection{Diversity of bacterial community}

In order to investigate the diversity and structure of the microbial communities, Illumina high-throughput sequencing technology was used to sequence the $16 \mathrm{~S}$ rRNA. In total, 509,008 effective sequences were obtained from all residue samples. At the $97 \%$ similarity level, all effective sequences were assigned to 5,490 OTUs and each sample contained 642 to 1733 OTUs. Furthermore, the coverage of effective sequences in each sample was higher than $98 \%$, and all rarefaction curves tended to approach the saturation plateau. The rarefaction curve showed that a deeper sequencing depth would not cause an obvious increase in observed OTU number, which indicated that the sequencing depth was adequate for further analysis (Fig.2a).

Natural weathering processes promoted bacterial diversity in bauxite residue. The number of OTUs and parameter indices (Chao1, Shannon and Shannoneven) of microbial communities increased significantly from unweathered to old weathered sites $(\mathrm{P}<0.05)$, but the indices were not significantly different between those of unweathered and young weathered locations (except Chao) (Fig.2). 

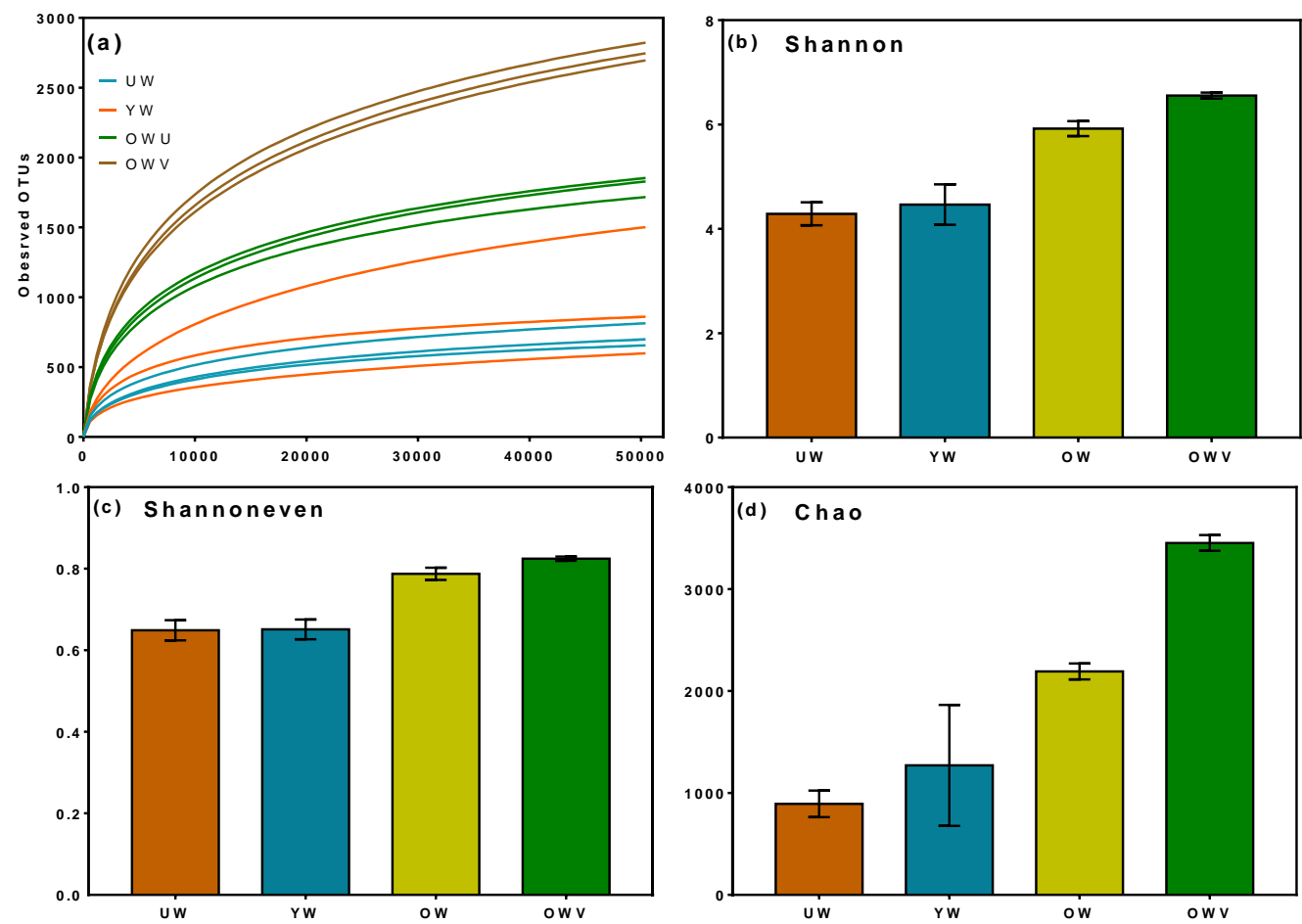

Fig. 2. Alpha diversity of bauxite residue during weathering process. (a) Observed OTUs, (b) Shannon diversity (c) Shannoneven evenness diversity, (d) Chao richness.

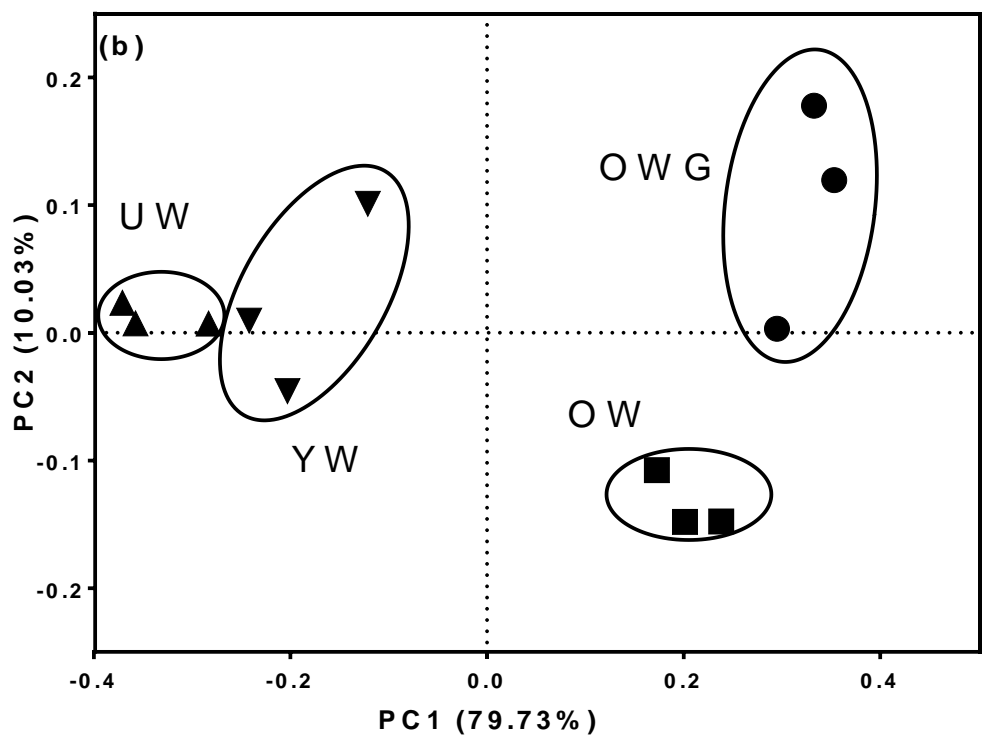

Fig. 3. Principal coordinate analysis (PCoA) of bacteria community composition for bauxite residue from different stages of weathering.

Principal coordinate analysis (PCoA) (Fig. 3) revealed that the bacterial communities in UW and YW clustered closely and grouped separately from those in OW and OWV. Coordinate axes 1, 2, and 3 (PC1, PC2, and PC3) can explain 79.73\%, 10.03\% and 3.98\% of the variation. The high explanation (PC1) in the first principal-coordinate axis revealed that the bacterial structure of residue samples was significantly changed. 


\subsection{Composition of bacterial community}

Microbial composition at the phylum level (relative abundance $>0.1 \%$ ) is shown in Fig. 4. A total of 31 phyla were identified across all residue samples. Firmicutes (6.18\%-33.8\%), Actinobacteria (8.9\%-32.3\%), Chloroflexi (6.8\%-25.3\%), Proteobacteria (10.9\%-19.5\%), Acidobacteria $(<1 \%-18.8 \%)$, Planctomycetes (1.0\%-13.7\%) and Deinococcus-Thermus (2.3\%-5.6\%). These seven phyla accounted for $89.9-92.9 \%$ of the effective sequences. Bacterial community distribution pattern also differed between residue samples from the different locations (Fig. 4). In unweathered residue (UW) samples, the most abundant phyla were Firmicutes and Actinobacteria, accounting for 29.5\% - 53.7\% and $26.2 \%-40.5 \%$ of all the sequences. Following Actinobacteria, the phyla were dominanted by Chloroflexi and Proteobacteria, accounting for a low abundance with a prevalence of $8.1 \%$ and $9.2 \%$, respectively. Other phyla that existed in UW residue samples were Deinococcus-Thermus (1.8-5.3\%), Gemmatimonadetes $(1.1 \%-2.8 \%)$ and Bacteroidetes (0.7\%-1.5\%). Natural weathering processes significantly changed the structure of bacterial communities in bauxite residue. Natural weathering processes significantly decreased the abundance of Firmicutes and Actinobacteria, whereas they increased the abundance of Chloroflexi (YW 17.4\%, OW 27.9\%). Furthermore, several new taxonomic groups including Acidobacteria (OW 9.5\%) and Planctomycetes (YW 1.3\%, OW 9.8\%), which are typical bacterial populations in soils, were found to be enriched. During long-term weathering processes, spontaneous vegetation encroachment occurred randomly at some sites. The vegetation colonization further increased the abundance of Acidobacteria (OWV $13.7 \%$ ) and Planctomycetes (OWV $18.8 \%$ ) and Proteobacteria (OWV).

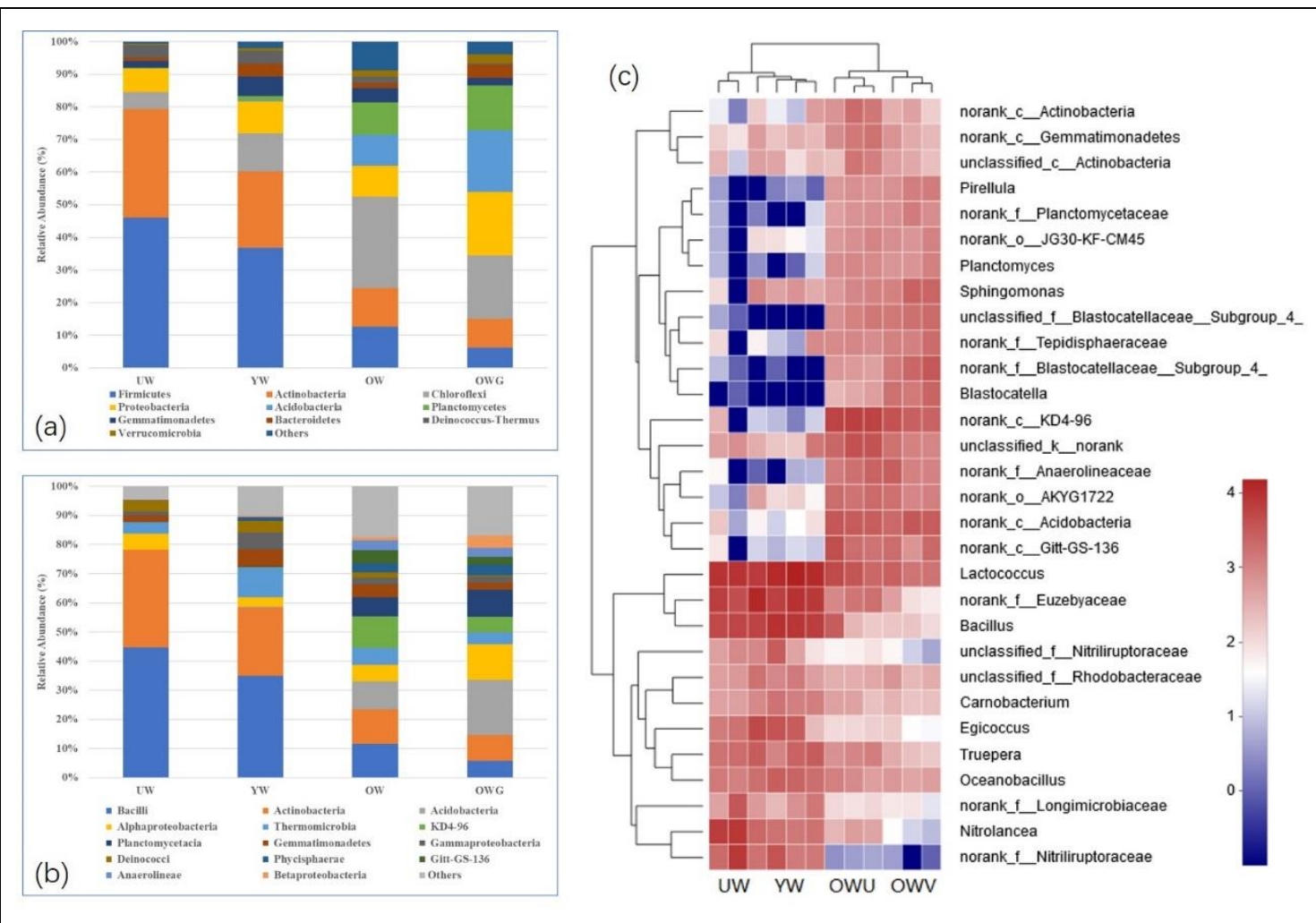

Fig. 4. Relative abundance of bacterial community in residue samples with different weathering histories at the (a) phylum level, (b) class level and (c) genera level

At the class level, a total of 61 classes were obtained across all residue samples (Table S4). 14 classes including Bacilli, Actinobacteria, Acidobacteria, Alphaproteobacteria, Thermomicrobia, 
KD4-96, Planctomycetacia, Gemmatimonadetes, Gammaproteobacteria, Deinococci, Phycisphaerae, Gitt-GS-136, Anaerolineae and Betaproteobacteria (defined as $>2 \%$ of the total effective sequences), accounted for 82.5 to $95.4 \%$ in each sample. The relative abundances of Actinobacteria, Bacilli and Deinococci were significantly higher at the unweathered (UW) and young weathered (YW) sites compared to the old weathered (OW and OWV) sites ( $\mathrm{P}<0.05$; Table S5). The relative abundances of Acidobacteria, Alphaproteobacteria, KD4-96, Planctomycetacia, Phycisphaerae, Gitt-GS-136, Anaerolineae, and Betaproteobacteri were however significantly higher in the two old weathered sites (OW and OWV) compared to the unweathered (UW) and young weathered (YW) sites (P<0.05). Bacterial composition at the class level revealed significant differences between OW and OWV sites (Table S4). The relative abundances of Actinobacteria, Bacilli, KD4-96, Thermomicrobia, Gitt-GS-136, and Gemmatimonadetes were significantly higher in OW sites than in OWV sites, whereas the relative abundances of Acidobacteria, Alphaproteobacteria, Planctomycetacia, Phycisphaerae, and Betaproteobacteria were significantly higher in OWV sites than those at OW sites.

For a more detailed analysis, a hierarchically clustered heat map based on the Bray-Curtis similarity index was generated to exhibit the hierarchical relationships of the top 30 genera among the 12 residue samples (Fig. 4c). The heat map revealed that the most often detected bacterial genera and the distribution characteristics of the higher abundance genera were different in residue samples with different weathering histories. In UW and YW residue, the most abundant genera were Lactococcus followed by norank $f \_$Euzebyaceae, Bacillus, Nitrolancea, norank_f_Nitriliruptoraceae, Truepera, Egicoccus, Oceanobacillus, unclassified_f_Rhodobacteraceae, and Carnobacterium. The abundance of these groups was significantly higher than those in OW and OWV sites $(\mathrm{P}<0.05)$. However, the abundant genera changed following long-term weathering. In OW and OWV sites, the most abundant genera were norank_c_KD4-96, followed by norank_c__Acidobacteria, Lactococcus, norank_c_Gitt-GS-136, Sphingomonas, norank_f_Anaerolineaceae, norank_o_AKYG1722, norank_f_Blastocatellaceae and norank_f_Tepidisphaeraceae. The abundance of these groups was significantly higher than those in UW and YW sites $(\mathrm{P}<0.05)$.

Linear discriminant analysis (LDA) effect size (LEfSe) was used to detect groups or species causing significant differences in bauxite residue with different weathering histories. As shown in Fig. 5(a), 23 bacteria classes exhibited statistically significant differences among the different weathered residue sites with an LDA threshold of 4.0 (Fig. 5b). Specifically, Bacilli (class), Firmicutes (phyla), Actinobacteria (class), Actinobacteria (phyla), Lactobacillales (order) were enriched in UW. Acidobacteria (phyla), Acidobacteria (class), Proteobacteria (phyla), Planctomycetes (phyla), Blastocatellaceae_Subgroup_4_(family) were enriched in OW (Fig. 5c). 

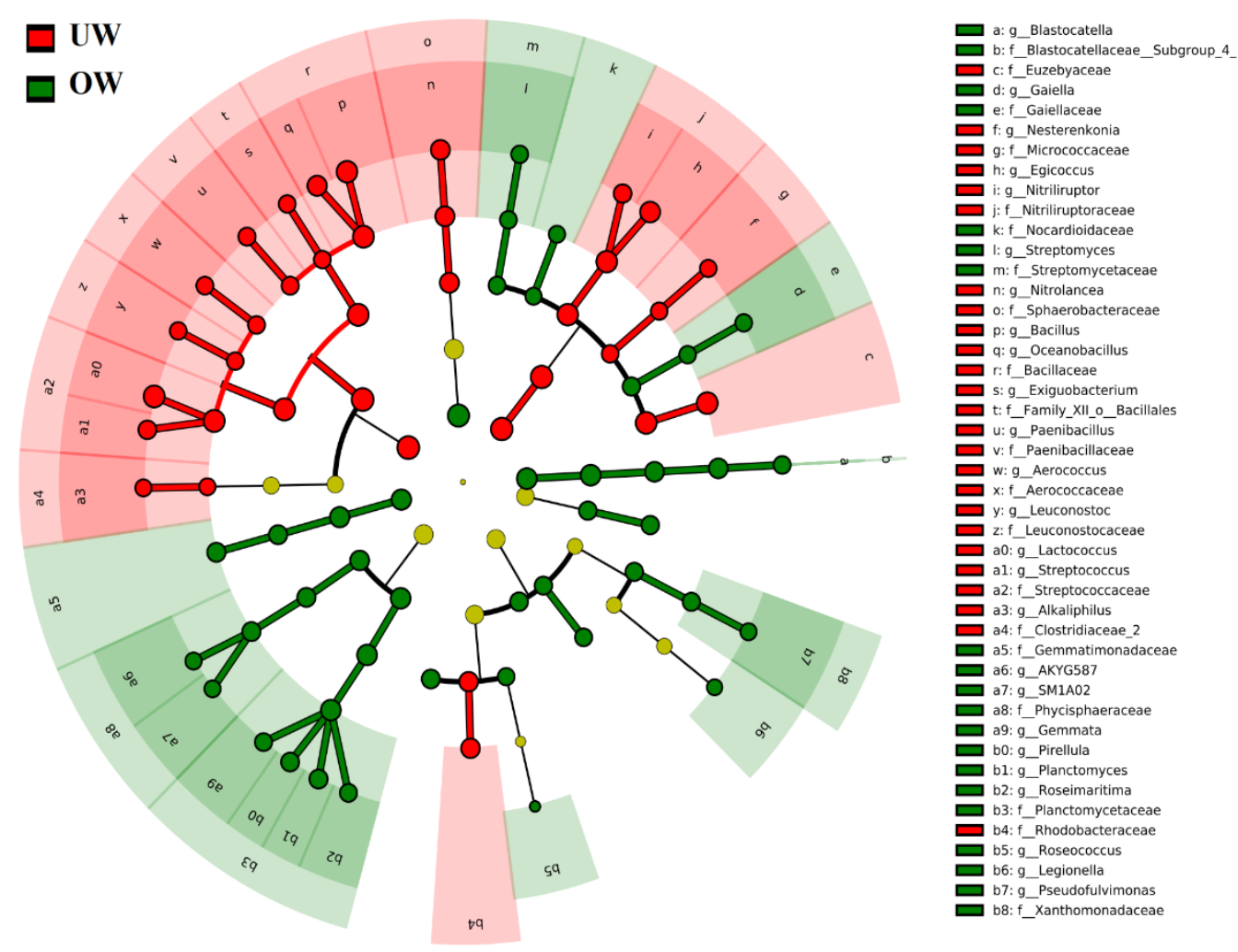

Fig. 5. LEFSe analysis of bacterial community in UW and OW residue sites. Yellow circles represent non-significant differences in abundance between UW and OW soils. Taxa enriched in UW samples with a positive LDA score (red), and taxa enriched in OW samples have a negative score (green).

\subsection{Correlation between bacterial community and residue property}

In this study, six parameters, including $\mathrm{pH}, \mathrm{EC}, \mathrm{ESP}, \mathrm{TOC}, \mathrm{TN}$ and $\mathrm{AP}$ were taken into consideration to investigate the relative contributions to bacterial communities. The Shannon index was significantly positively correlated with the contents of TOC, TN and AP, whilst negativley correlated to residue pH, EC and ESP (Fig. 6).

The RDA results showed that physico-chemical properties of bauxite residue had significant effects on the bacterial community. Overall, the first two axes explained $88.85 \%$ of the variation of microbial composition, and the correlation of species-environment of both axes was > 95\% (pseudo-canonical correlation). It suggested that there were remarkable correlations between microbial community composition and environmental properties.

For a more detailed analysis, linear-regression analysis was conducted to reveal the relationships between residue properties and bacterial taxa. High alkalinity and salinity showed significant influence on bacterial communities. The relative abundance of Fimicutes and Actinobacteria were positively correlated with $\mathrm{pH}, \mathrm{EC}$, and ESP $(\mathrm{P}<0.001)$, while Acidobacteria, and Planctomycetes were negatively correlated with residue $\mathrm{pH}(\mathrm{P}<0.001)$. The species from Chloroflexi and Proteobacteria showed a weak correlation with pH, EC, and ESP. The relative abundance of Chloroflexi were positively correlated with $\mathrm{pH}$, EC, and ESP $(\mathrm{P}=0.03, \mathrm{P}=0.02$, $\mathrm{P}=0.03$, respectively). The Proteobacteria showed a weaker correlation with $\mathrm{EC}$ compared to $\mathrm{pH}$ and ESP. 


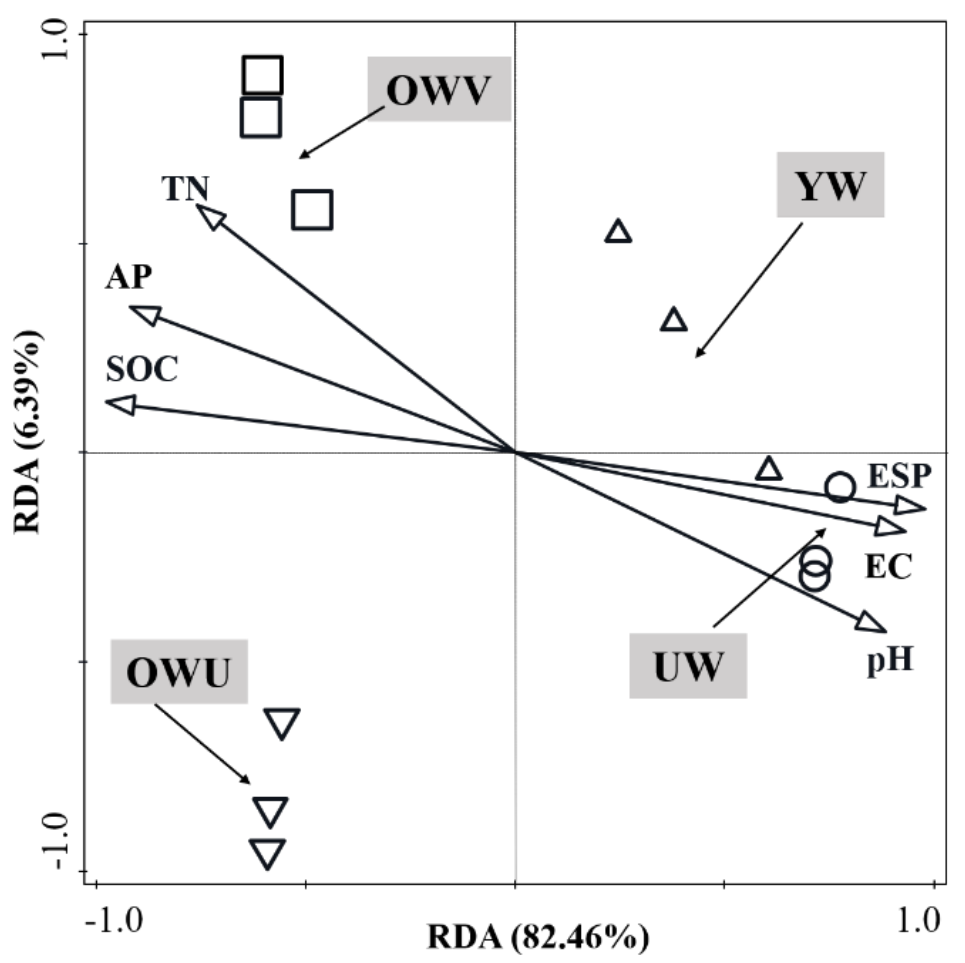

Fig .6. Redundancy analysis (RDA) of the microbial community and environmental parameters across all residue samples with different weathering histories.

Except for the high alkalinity and salinity, the variation in nutrient concentrations in bauxite residue also significantly influenced its bacterial communities. The relative abundances of Acidobacteria and Planctomycetes revealed significant positive correlations with the concentrations of TOC, TN and AP (all P < 0.05), whilst those of Firmicutes and Actinobacteria were significantly negatively correlated with the concentrations of TOC, TN and AP $(\mathrm{P}<0.05)$.

\section{Discussion}

\subsection{Effect of natural process on residue properties}

The long-term weathering process caused significant changes to the properties of bauxite residue. $\mathrm{pH}$ and EC of residues at the weathered sites were significantly lower than at the unweathered sites, which may be caused by wind erosion and water leaching. Kong et al. (2017a) reported that long-term natural weathering processes decreased the alkalinity and salinity of bauxite residue through the leaching of free hydroxides, carbonates and aluminates, and dissolution of alkalinity solids including sodalite, hydrogarnet and calcite. In addition, some bacterial communities may secrete organic acids, which benefit the reduction of alkalinity in bauxite residue (Hamdy and Williams, 2001). The contents of TOC, TN, and AP at the weathered sites were predominantly higher than those at the unweathered sites (Table 2); indicating that natural weathering processes enhanced the concentrations of nutrients in bauxite residue. Zhu et al. (2016) found that long-term weathering processes could promote the accumulation of organic carbon and aggregate formation in bauxite residue. This may be caused by the shift from haloalkaliphile-dominated assemblages to diverse soil species with diverse functions such as $\mathrm{C} / \mathrm{N}$ fixation (Santini et al., 2015). 


\subsection{Effect of natural process on bacterial community}

The abundance (16S gene abundance) of bacterial communities was higher in weathered sites than those in unweathered sites. Similar results were also observed in bacterial diversity indexes, indicating that natural weathering processes increased the bacterial diversity in bauxite residue. This has been demonstrated previously in the restoration of mine tailings (Li et al., 2015; Wu et al., 2018). At the weathered site, the establishment of vegetation generally promoted the development of bacterial communities by creating a nutrient enriched environment, with root exudates and organic acids. On the other hand, microorganisms were involved in the degradation of organic substances, $\mathrm{C} / \mathrm{N}$ fixation and the mobilization of mineral nutrition (Bao et al., 2019; Courty et al., 2010; Uroz et al., 2011), which were all beneficial to plant growth. Plant-microbe interactions at the restored site were conducive to the establishment of plants and improvement of soil quality, and finally promoted ecosystem reconstruction (Wu et al., 2018).

The composition of bacterial communities significantly changed during natural weathering processes (Figure 3). Bacterial communities in unweathered sites were dominated by Firmicutes and Actinobacteria. This finding contradicted a previous study with fresh bauxite residue which showed that Proteobacteria was the predominant bacterial phylum (Krishna et al., 2014; Santini et al., 2015). Firmicutes and Actinobacteria are considered to have strong metabolic capacities and are frequently found in alkaline lakes and hypersaline mats. However, long-term weathering dramatically changed the bacterial communities, which were dominated by Chloroflexi, Acidobacteria, Planctomycetes and Proteobacteria in old weathered sites. This partially coincides with the results from Schmalenberger (Schmalenberger et al., 2013), in which restoration resulted in the accumulation of Acidobacteria. Acidobacteria are generally acidophilic, and ubiquitous in various ecosystems, especially soils. The abundance of Acidobacteria in soils is correlated with soil pH (Jones et al., 2009). Acidobacteria can make up $20 \%$ of all bacteria in soils with a pH ranged from 7-8 (Lauber et al., 2009). Acidobacteria is divided into 26 subgroups (Barns et al., 2007), and the subgroups of Gp1, Gp2, Gp3, Gp4 and Gp6 are abundant in soil environments (Barns et al., 1999). In this study, the high abundances of Gp4 and norank_c_Acidobacteria dominated the weathered sites (Table S5). However, Wei et al. (Wei et al., 2019) reported that $\mathrm{Gp} 1, \mathrm{Gp} 2$ and $\mathrm{Gp} 3$ were abundant in the restored tailings ( $\mathrm{pH}=4.5-4.8)$. Griffiths et al. (Griffiths et al., 2011) found that low $\mathrm{pH}(\mathrm{pH}=4.3)$, medium $\mathrm{pH}(\mathrm{pH}=6.1)$ and high $\mathrm{pH}(\mathrm{pH}=8.2)$ soils were dominated by Gp1, Gp1 + Gp6 and Gp6, respectively.

Proteobacteria is another abundant bacterial phylum at weathered residue sites (Fig. 2 and Table S2). These results were consistent with many previous studies. For example, Santini et al. (Santini et al., 2015) found that the relative abundance of Proteobacteria ranged from $40-80 \%$ of all the sequences in bauxite residue. Proteobacteria often plays an important role in nitrogen cycling (Rick and Thomas, 2001). Proteobacteria may play a key role in phylogenetic, ecological and pathogenic values and participate in energy metabolism, such as the oxidation of organic and inorganic compounds and obtaining energy from light (Bryant and Frigaard, 2006). Proteobacteria often consist of four classes including Alpha-, Beta-, Gamma- and Deltaproteobacteria. In this study, Alphaproteobacteria and Betaproteobacteria increased whereas Gammaproteobacteria decreased during the natural weathering process. These results corresponded to the report of Liu et al (Liu et al., 2014). The relative abundance of Gammaproteobacteria increased with increasing soil $\mathrm{pH}$, while Alphaproteobacteria showed the opposite pattern. Shen et al. (Shen et al., 2013) also found a similar negative relationship between Alphaproteobacteria and soil pH in Changbai Mountain soils, while Lauber et al. (2009) and Chu et al. (2010) reported that the population of Alphaproteobacteria was positively correlated to soil $\mathrm{pH}$. 


\subsection{Relationship among bacterial community and residue properties}

Natural weathering processes improved residue properties and changed bacterial community structure at the disposal area. RDA analysis showed that residue properties including $\mathrm{pH}$, organic carbon, total nitrogen and available phosphorus were the major drivers of microbial community diversity (Fig. 3).

Many studies have demonstrated $\mathrm{pH}$ is the primary factor affecting soil microbiota in various types of soils (Fierer and Jackson, 2006; Shen et al., 2013; Griffiths et al., 2011), and have proposed that pH is a universal factor determining soil microbiota (Chu et al., 2010; Liu et al., 2014; Nacke et al., 2011). A decrease in $\mathrm{pH}$, such as soil acidification, may enhance the release of mineral nutrients for microbial growth and subsequently influence microbial community composition (Carson et al., 2007). In addition, high concentrations of $\mathrm{H}^{+}$or $\mathrm{OH}^{-}$in soil may restrict microbial community diversity by imposing stress on microbial colonization, and regulating the availability of nutrient elements (Cookson et al. 2007). Xiong et al. (2012) found that $\mathrm{pH}$ was an effective indicator to predict bacterial community structure in alkaline sediments. The results in our study also showed that residue $\mathrm{pH}$ could drive the development of bacterial communities. For instance, with the decrease of residue $\mathrm{pH}$, the relative abundance of Acidobacteria increased. This was similar to the distribution patterns of Acidobacteria across the related pH gradient (Jones et al., 2009; Dimitriu and Grayston, 2010; Shen et al., 2013). Furthermore, the relative abundance of Alphaproteobacteria increased at a lower $\mathrm{pH}$, which contrasted with the results in other studies (Shen et al., 2013). It was worth noting that these soils were weakly acidic or nearly neutral (3.5-6.5), whist the $\mathrm{pH}$ in residue samples ranged from 9.4 to 11.3. The different $\mathrm{pH}$ environments may result in different variations in abundance of Alphaproteobacteria.

Besides $\mathrm{pH}$, other environmental variances are also important for the geographic distribution of microbial communities in different environments (Freedman and Zak, 2015). Huang et al. (2013) demonstrated that bacterial communities in hot springs were predominantly correlated with temperature, sulfur, total nitrogen and calcium content. Azarbad et al., (2013) observed that the bacterial communities in heavy metal contaminated soils was driven by soil organic matter. In this study, long-term natural process accumulated nutrients in bauxite residue, including TOC, TN and AP (Table 1). The relative abundances of six major phyla, including Proteobacteria, Acidobacteria, Firmicutes, Actinobacteria, Chloroflexi and Planctomycetes, had significant correlations with the contents of TOC, $\mathrm{TN}$ and AP. Among these groups, Actinobacteria and Firmicutes showed negative correlation with TOC, TN and AP in bauxite residue, whilst Acidobacteria, Proteobacteria, Chloroflexi and Planctomycetes showed positive correlation with these indexes (Fig. S5-S7). This was consistent with the findings from Schmalenberger et al. (2013). At the BRDA restored for 12 years, Schmalenberger et al. (2013) found that Verrucomicrobia, Acidobacteria, and Proteobacteria were closely related to the contents of TC and TN. In addition, the evolution of bacterial communities from haloalkaliphile-dominated assemblages may respond from the accumulation of Planctomycetes in bauxite residue (Santini et al., 2015). However, the significant relationship between Chloroflexi and nutrients here have not been found in other research (Schmalenberger et al., 2013). This may be caused by the unique bacterial communities in this study, from which Chloroflexi made a large contribution. In well-remediated bauxite residue, its abundance was quite low and therefore showed no significant correlation with residue proprieties. 


\section{Conclusion}

This study has revealed the dynamic development of diversity and structure in microbial communities following natural weathering processes at bauxite residue disposal areas. Alkalinity and salinity decreased, whilst nutrient elements improved at the old weathered site. Both microbial diversity index and microbial community structure differed significantly following long-term residue weathering. The dominant phyla were Firmicutes and Actinobacteria at the unweathered site, whilst Proteobacteria, Chloroflexi, Acidobacteria and Planctomycetes dominated in the old weathered residues. Twenty-one biomarkers were found in the bauxite residue through a linear discriminate analysis (LDA) effect size (LEfSe) analysis. LEfSe analysis revealed that the biomarker changed significantly from Firmicutes (phyla) and Actinobacteria (class) in unweathered residues to Acidobacteria (phyla) and Planctomycetes (phyla) in old weathered residues. Soil microbial community composition and diversity were mainly regulated by soil nutrients (TOC, TN and AP) and $\mathrm{pH}$, whilst soil nutrients were the major factors. This study has improved our understanding of microbial diversity in bauxite residue disposal areas and further studies should focus on functional gene prediction to reveal possible mechanisms of metabolic pathways of microorganisms on soil formation in bauxite residue disposal areas.

\section{References}

\footnotetext{
Banning, N.C., Phillips I.R., Jones D.L., Murphy D.V. Development of Microbial Diversity and Functional Potential in Bauxite Residue Sand under Rehabilitation. Restoration Ecology 2011; 19: 78-87.

Bao, Y.Y., Dolfing J., Wang B.Z., Chen R.R., Huang M.S., Li Z.P., et al. Bacterial communities involved directly or indirectly in the anaerobic degradation of cellulose. Biology and Fertility of Soils 2019; 55: 201-211.

Barns, S.M., Cain E.C., Sommerville L., Kuske C.R. Acidobactetia phylum sequences in uranium-contaminated subsurface sediments greatly expand the known diversity within the phylum. Applied and Environmental Microbiology 2007; 73: 3113-3116.

Barns, S.M., Takala S.L., Kuske C.R. Wide distribution and diversity of members of the bacterial kingdom Acidobacterium in the environment. Applied and Environmental Microbiology 1999; 65: 1731-1737.

Bryant, D.A., Frigaard N.U. Prokaryotic photosynthesis and phototrophy illuminated. Trends Microbiol 2006; 14: 488-96.

Chen, B., Roos P., Zhu Y.-G., Jakobsen I. Arbuscular mycorrhizas contribute to phytostabilization of uranium in uranium mining tailings. Journal of Environmental Radioactivity 2008; 99: 801-810.

Chu, H.Y., Fierer N., Lauber C.L., Caporaso J.G., Knight R., Grogan P. Soil bacterial diversity in the Arctic is not fundamentally different from that found in other biomes. Environmental Microbiology 2010; 12: 2998-3006.

Courtney, R., Harrington T. Growth and Nutrition of Holcus Lanatus in Bauxite Residue Amended with Combinations of Spent Mushroon Compost and Gypsum. LAND DEGRADATION \& DEVELOPMENT 2012; 23: 144-149.

Courtney, R., Kirwan L. Gypsum amendment of alkaline bauxite residue - Plant available aluminium and implications for grassland restoration. ECOLOGICAL ENGINEERING 2012; 42: 279-282.

Courty, P.E., Buee M., Diedhiou A.G., Frey-Klett P., Le Tacon F., Rineau F., et al. The role of ectomycorrhizal communities in forest ecosystem processes: New perspectives and emerging concepts. Soil Biology \& Biochemistry 2010; 42: 679-698.

Dhawi, F., Datta R., Ramakrishna W. Mycorrhiza and heavy metal resistant bacteria enhance growth, nutrient uptake and alter metabolic profile of sorghum grown in marginal soil. Chemosphere 2016; 157: 33-41.
} 
Fierer, N., Nemergut D., Knight R., Craine J.M. Changes through time: integrating microorganisms into the study of succession. Res Microbiol 2010; 161: 635-42.

Fuller, R.D., Nelson E.D.P., Richardson C.J. Reclamation of Red Mud (Bauxite Residues) Using Alkaline-Tolerant Grasses with Organic Amendments1. 1982; 11: 533-539.

Gomes, H.I., Mares W.M., Rogerson M., Stewart D.I., Burke I.T. Alkaline residues and the environment: a review of impacts, management practices and opportunities. Journal of Cleaner Production 2016; 112: 3571-3582.

Grandlic, C.J., Mendez M.O., Chorover J., Machado B., Maier R.M. Plant growth-promoting bacteria for phytostabilization of mine tailings. ENVIRONMENTAL SCIENCE \& TECHNOLOGY 2008; 42: 2079-2084.

Griffiths, R.I., Thomson B.C., James P., Bell T., Bailey M., Whiteley A.S. The bacterial biogeography of British soils. Environmental Microbiology 2011; 13: 1642-1654.

Hackl, E., Zechmeister-Boltenstern S., Bodrossy L., Sessitsch A. Comparison of diversities and compositions of bacterial populations inhabiting natural forest soils. Applied and Environmental Microbiology 2004; 70: 5057-5065.

Hamdy, M.K., Williams F.S. Bacterial amelioration of bauxite residue waste of industrial alumina plants. JOURNAL OF INDUSTRIAL MICROBIOLOGY \& BIOTECHNOLOGY 2001; 27: 228-33.

Jones, B.E.H., Haynes R.J. Bauxite Processing Residue: A Critical Review of Its Formation, Properties, Storage, and Revegetation. Critical Reviews in Environmental Science and Technology 2011; 41: 271-315.

Jones, B.E.H., Haynes R.J., Phillips I.R. Effect of amendment of bauxite processing sand with organic materials on its chemical, physical and microbial properties. Journal of Environmental Management 2010; 91: 2281-2288.

Jones, B.E.H., Haynes R.J., Phillips I.R. Influence of organic waste and residue mud additions on chemical, physical and microbial properties of bauxite residue sand. Environmental Science and Pollution Research 2011; 18: 199-211.

Jones, R.T., Robeson M.S., Lauber C.L., Hamady M., Knight R., Fierer N. A comprehensive survey of soil acidobacterial diversity using pyrosequencing and clone library analyses. ISME JOURNAL 2009; 3: 442-453.

Kong, X.F., Guo Y., Xue S.G., Hartley W., Wu C., Ye Y.Z., et al. Natural evolution of alkaline characteristics in bauxite residue. JOURNAL OF CLEANER PRODUCTION 2017a; 143: 224-230.

Kong, X.F., Guo Y., Xue S.G., Hartley W., Wu C., Ye Y.Z., et al. Natural evolution of alkaline characteristics in bauxite residue. Journal of Cleaner Production 2017b; 143: 224-230.

Krishna, P., Babu A.G., Reddy M.S. Bacterial diversity of extremely alkaline bauxite residue site of alumina industrial plant using culturable bacteria and residue 16S rRNA gene clones. Extremophiles 2014; 18: 665-676.

Kuiper, I., Lagendijk E.L., Bloemberg G.V., Lugtenberg B.J.J. Rhizoremediation: A Beneficial Plant-Microbe Interaction. Molecular Plant-Microbe Interactions 2004; 17: 6-15.

Lauber, C.L., Hamady M., Knight R., Fierer N. Pyrosequencing-Based Assessment of Soil pH as a Predictor of Soil Bacterial Community Structure at the Continental Scale. Applied and Environmental Microbiology 2009; 75: 5111-5120.

Li, Y.Y., Chen L.Q., Wen H.Y. Changes in the composition and diversity of bacterial communities 13 years after soil reclamation of abandoned mine land in eastern China. Ecological Research 2015; 30: 357-366.

Liu, J.J., Sui Y.Y., Yu Z.H., Shi Y., Chu H.Y., Jin J., et al. High throughput sequencing analysis of biogeographical distribution of bacterial communities in the black soils of northeast China. SOIL BIOLOGY \& BIOCHEMISTRY 2014; 70: 113-122.

Lynn, T.M., Ge T.D., Yuan H.Z., Wei X.M., Wu X.H., Xiao K.Q., et al. Soil Carbon-Fixation Rates and AsTOCiated Bacterial Diversity and Abundance in Three Natural Ecosystems. Microbial Ecology 2017; 73: 645-657.

McCarthy, A.J., Williams S.T. Actinomycetes as agents of biodegradation in the environment—a review. Gene 1992; 115: 189-192.

Mendez, M.O., Maier R.M. Phytostabilization of mine tailings in arid and semiarid environments - An emerging remediation technology. Environmental Health Perspectives 2008; 116: 278-283.

Nassal, D., Spohn M., Eltlbany N., Jacquiod S., Smalla K., Marhan S., et al. Effects of phosphorus-mobilizing bacteria on tomato growth and soil microbial activity. Plant and Soil 2018; 427: 17-37. 
Parks, D.H., Tyson G.W., Hugenholtz P., Beiko R.G. STAMP: statistical analysis of taxonomic and functional profiles. Bioinformatics 2014; 30: $3123-3124$

Power, G., Grafe M., Klauber C. Bauxite residue issues: I. Current management, disposal and storage practices. HYDROMETALLURGY 2011; $108: 33-45$

Rashid, M.I., Mujawar L.H., Shahzad T., Almeelbi T., Ismail I.M.I., Oves M. Bacteria and fungi can contribute to nutrients bioavailability and aggregate formation in degraded soils. Microbiological Research 2016; 183: 26-41.

Rayment, G.E., Higginson F.R. Australian laboratory handbook of soil and water chemical methods. 1992.

Santini, T.C., Warren L.A., Kendra K.E. Microbial Diversity in Engineered Haloalkaline Environments Shaped by Shared Geochemical Drivers Observed in Natural Analogues. Applied and Environmental Microbiology 2015; 81: 5026-36.

Schmalenberger, A., O'Sullivan O., Gahan J., Cotter P.D., Courtney R. Bacterial communities established in bauxite residues with different restoration histories. ENVIRONMENTAL SCIENCE \& TECHNOLOGY 2013; 47: 7110-9.

Schweinsberg-Mickan, M.S.Z., Muller T. Impact of effective microorganisms and other biofertilizers on soil microbial characteristics, organic-matter decomposition, and plant growth. Journal of Plant Nutrition and Soil Science 2009; 172: 704-712.

Shen, C.C., Xiong J.B., Zhang H.Y., Feng Y.Z., Lin X.G., Li X.Y., et al. Soil pH drives the spatial distribution of bacterial communities along elevation on Changbai Mountain. Soil Biology \& Biochemistry 2013; 57: 204-211.

Uroz, S., Oger P., Lepleux C., Collignon C., Frey-Klett P., Turpault M.P. Bacterial weathering and its contribution to nutrient cycling in temperate forest ecosystems. Research in Microbiology 2011; 162: 820-831.

Wei, Z., Hao Z., Li X., Guan Z., Cai Y., Liao X. The effects of phytoremediation on soil bacterial communities in an abandoned mine site of rare earth elements. Sci Total Environ 2019; 670: 950-960.

Wong, J. Use Of Waste Gypsum In The Revegetation On Red Mud Deposits: A Greenhouse Study. Waste Management \& Research 1993; 11 249-256.

Wu, Z.X., Yu F.X., Sun X.Y., Wu S.L., Li X.H., Liu T.Y., et al. Long term effects of Lespedeza bicolor revegetation on soil bacterial communities in Dexing copper mine tailings in Jiangxi Province, China. Applied Soil Ecology 2018; 125: 192-201.

Xue, S.G., Wu Y.J., Li Y.W., Kong X.F., Zhu F., William H., et al. Industrial wastes applications for alkalinity regulation in bauxite residue: A comprehensive review. Journal of Central South University 2019; 26: 268-288.

Xue, S.G., Zhu F., Kong X.F., Wu C., Huang L., Huang N., et al. A review of the characterization and revegetation of bauxite residues (Red mud). Environmental Science and Pollution Research 2016; 23: 1120-1132.

Zhu, F., Li X.F., Xue S.G., Hartley W., Wu C., Han F.S. Natural plant colonization improves the physical condition of bauxite residue over time. Environmental Science and Pollution Research 2016; 23: 22897-22905.

Azarbad, H., Niklinska M., van Gestel C.A.M., van Straalen N.M., Roling W.F.M., Laskowski R. Microbial community structure and functioning along metal pollution gradients. Environmental Toxicology and Chemistry 2013; 32: 1992-2002.

Carson, J.K., Rooney D., Gleeson D.B., Clipson N. Altering the mineral composition of soil causes a shift in microbial community structure. Fems Microbiology Ecology 2007; 61: 414-423.

Fierer, N., Jackson R.B. The diversity and biogeography of soil bacterial communities. Proceedings of the National Academy of Sciences of the United States of America 2006; 103: 626-631

Freedman, Z., Zak D.R. Soil bacterial communities are shaped by temporal and environmental filtering: evidence from a long-term chronosequence. $2015 ; 17: 3208-3218$

Shen, C.C., Xiong J.B., Zhang H.Y., Feng Y.Z., Lin X.G., Li X.Y., et al. Soil pH drives the spatial distribution of bacterial communities along elevation on Changbai Mountain. Soil Biology \& Biochemistry 2013; 57: 204-211. 